\title{
Intercambio cultural desigual y crisis civilizatoria. Desafíos del cambio cultural y el desarrollo humano
}

Unequal cultural exchange and crisis of civilization. Challenges of cultural change and human development

\author{
Raúl Delgado Wise \\ Presidente de la Red Internacional de Migración y Desarrollo, Coordinador de la Cátedra UNESCO sobre Migración, Desarrollo \\ y Derechos HumanosDoctorado en Estudios y Profesor del Doctorado en Estudios del Desarrollo (Universidad Autónoma de \\ Zacatecas) \\ rdwise@estudiosdeldesarrollo.net
}

\section{Humberto Márquez Covarrubias}

Responsable del Programa de Doctorado en Estudios del Desarrollo de la Universidad Autónoma de Zacatecas. hmarquez@estudiosdeldesarrollo.net

\section{ANIVERSARIO DE LA GAZETA DE ANTROPOLOGÍA NÚMERO COORDINADO POR FRANCISCO CHECA OLMOS Y CELESTE JIMÉNEZ DE MADARIAGA}

La noción de cultura hegemónica tiene como principios los valores del libre mercado, la democracia electoral, el individualismo, el consumismo y el entretenimiento. La cultura se convierte en un espécimen mercantil que galvaniza las prácticas sociales, tradiciones y valores con los preceptos de la economía global que tiene en las grandes corporaciones multinacionales y las industrias de la información y el entretenimiento los grandes vertederos de las pautas socioculturales de la sociedad contemporánea. Los desenfrenos culturales de la globalización neoliberal han desembocado en una crisis cuyo sustrato va más allá del resquebrajamiento de los circuitos financieros, pues hunde sus raíces en la matriz civilizatoria: un cortocircuito en el sistema reproducción de la vida humana propicia una crisis humanitaria de severa proporciones que toma forma en el desempleo galopante, la epidemia de hambre, la propagación de enfermedades curables, la migración forzada, la degradación del medio ambiente y la inseguridad humana. En el perímetro de la cultura subalterna, donde anida la indignación y la resistencia ante los riesgos y peligros emanados de la crisis civilizatoria está germinando una energía social, sobre todo entre los jóvenes, que llama la atención sobre la necesidad de impulsar un cambio cultural, donde la producción de conocimiento, tecnología y arte, en conjunción con el pensamiento crítico, creativo y propositivo, encuentren nuevos senderos hacia un desarrollo humano generalizado, el bien común y la democracia real.
\end{abstract}

\section{ABSTRACT}

The notion of hegemonic culture has as principles of free-market values, electoral democracy, individualism, consumerism, and entertainment. Culture becomes a commercial product, galvanizing social practices, traditions, and values with the precepts of the global economy in which large multinational corporations and industries of information and entertainment constitute dumps of large contemporary cultural patterns of society. The cultural debauchery of neoliberal globalization have led to a crisis wherein substrate is beyond the breakdown of the financial circuits, as rooted in matrix of civilization: a short-circuit in the reproduction system of human life promotes a severe humanitarian crisis that takes the form of unemployment, epidemic hunger, the spread of curable diseases, forced migration, environmental degradation, and human insecurity. On the perimeter of subaltern culture, harbouring indignation as well as resistance to the hazards and risks arising from the crisis of civilization is germinating social energy, especially among young people, which draws attention to the need to promote a cultural change, where the production of knowledge, technology and art, in conjunction with critical thinking, creative and proactive, find new paths to widespread human development, the common good and real democracy.

PALABRAS CLAVE

intercambio cultural desigual I violencia I crisis civilizatoria I cambio cultural I transformación social KEYWORDS

unequal cultural exchange I violence I crisis of civilization I culture change I social transformation 


\section{Introducción}

Más que un conjunto articulado de caracteres e identidades, la noción de cultura que empleamos en este trabajo se refiere a un sistema de prácticas y valores cuyo sentido y significado es producto del devenir histórico, del entramado estructural de relaciones sociales y de los proyectos políticos e institucionales de las clases, grupos y movimientos sociales. En tanto referente colectivo, la cultura contiene pautas ideológicas, éticas y políticas que orientan la actuación de los sujetos, por lo que pueden ser consideradas como dispositivos conceptuales o abstracciones simbólicas, en tanto que su puesta en práctica expresa la acción social de los sujetos.

El desafío civilizatorio de la cultura se entiende como la praxis social orientada a mejorar la vida humana en sociedad, lo cual incluye la relación con el medio ambiente, a través del empleo de los recursos de la inteligencia, la invención y la creatividad humana. El proceso de construcción social del desarrollo humano dispone de un amplio abanico de recursos: el conocimiento y saber; la educación, ciencia y tecnología; el arte; la ética, política y gobierno; la economía, empresa y trabajo, y las leyes, normas y costumbres. El gran desafío de la humanidad es emplear estos recursos y energías sociales para saciar los intereses del capital y el poder o para satisfacer las necesidades de la mayoría de la población. Existen, sin embargo, muchos intersticios que parecieran escapar a ese desafío, por estar ubicados en prácticas que discrepan de los proyectos del Estado y el capital, y que tienden a recrear costumbres y tradiciones. Sin embargo, estos ámbitos de comunidad no escapan a los designios de la relación social dominante, la lógica del capital.

Un entramado de relaciones sociales tiene lugar en diversos planos y niveles, que conjugan a diversas clases sociales, grupos étnicos, sectores demográficos, organizados para la producción y reproducción de la vida humana. El trabajo productivo (valorización del capital) y el trabajo reproductivo (reproducción social) están orquestados por pautas diseñadas por los gestores del capital y el poder. Los márgenes de autonomía y autodeterminación son estrechos, aunque deseables.

Los estudios culturales marcan un énfasis en los terrenos de la subjetividad humana y en menor medida en la cultura material. Desde nuestra apreciación ambos elementos son insoslayables, y sólo pueden separarse para cumplir algunos objetivos analíticos, pero en la realidad actúan imbricados. Otro énfasis es la consideración de los individuos, comunidades o grupos identitarios como unidad de análisis, a partir de sus relaciones interpersonales, descuidando las relaciones sociales con otros conjuntos sociales e institucionales.

Una forma de entender este pronunciamiento metodológico es postular la idea de que las expresiones culturales son manifestaciones de las relaciones sociales de producción y reproducción del orden social vigente, por lo que son encarnaciones de los proyectos sociales en disputa. En términos genéricos la cultura se presenta como un ámbito de dominio de la humanidad abstracta sobre la infraestructura natural, las instituciones, los conjuntos humanos y el conocimiento para el desarrollo humano, pero una mirada más aguzada nos permite comprender que las élites sociales imponen sus intereses hegemónicos, valga decir, la cultura dominante. En contrapartida, existen culturas varias que expresan encuadres subalternos y posiciones contrahegemónicas.

Una noción crucial de la cultura es la de desarrollo, porque concita un proyecto civilizatorio, una construcción social donde se disputan distintas visiones del mundo. El desarrollo humano representa la representación cultural de mayor contenido civilizatorio, porque concede una dimensión humana de alta densidad a la praxis social.

\section{Desigualdades culturales}

En el mundo contemporáneo privan dinámicas de desarrollo desigual que, por una parte, propician la innovación científico-tecnológica, la conformación de grandes empresas, la ampliación de los mercados, el refinamiento de las manifestaciones artísticas y el fortalecimiento de las instituciones, pero por la otra 
se concentra el poder, la riqueza y el conocimiento en pocas manos, en los miembros de las élites sociales y en los grupos sociales que les son afines. El desarrollo desigual puede desdoblarse en dos niveles: espacial y social.

Los llamados países centrales o desarrollados, articulados alrededor de la gran potencia mundial, Estados Unidos, concentran a las principales corporaciones multinacionales que despliegan en el mundo cadenas de producción que controlan los procesos de financiamiento, producción, distribución, inversión e innovación. Asimismo, este núcleo de países detenta una suerte de poder global mediante un entramado de instituciones financieras, militares y diplomáticas que difunden los intereses geoestratégicos de las grandes potencias. En contrapartida, los llamados países periféricos, subdesarrollados o poscoloniales, han perdido la soberanía política, económica, laboral y alimentaria, pese a que prácticamente la totalidad se han declarado como independientes (Amin 2010, Dussel 2011). Estos países mantienen relaciones de intercambio desigual con los centrales, de manera que trasladan, de manera sistemática, excedente económico y recursos naturales y humanos, que conforman el fundamento material y subjetivo para alimentar dinámicas de acumulación, crecimiento y desarrollo. Las élites nacionales son beneficiarias del sistema de dominación, pues logran preservar sus intereses inmediatos, pero resultan incapaces de promover la invención social para el desarrollo. En las periferias se profundiza el subdesarrollo y la dependencia.

Al seno de los países centrales y periféricos, las élites sociales concentran poder, capital y riqueza. Para ello, logran someter los elementos culturales generados por esfuerzos colectivos, como el conocimiento, la ciencia, la tecnología, la infraestructura, las instituciones. Las expresiones más logradas de la ciencia se vuelcan a favor de los objetivos fijados por las élites. En contraste, la mayoría de la población padece condiciones degradantes de vida y trabajo. Incluso pierde la capacidad de controlar sus propias energías y aspiraciones, para servir a los intereses del proyecto dominante. Despersonalizados y enajenados, los proletarios de la agricultura, industria, comercio y servicios, y los trabajadores de la ciencia, la tecnología y la cultura, no logran generar una conciencia colectiva, que aparte de reconocer el lugar que ocupan en la estructura social, puedan imaginar otros mundos, otras culturas otras formas de estar en la civilización. Las culturas de las clases subalternas son despreciadas y señaladas como "culturas populares", expresiones de formas anacrónicas de la vida social.

Entre países centrales y periféricos, clases dominantes y subalternas, se imponen relaciones culturales diferenciadas y contradictorias que dan forma a una suerte de intercambio cultural desigual. Algunos elementos que dan cuenta de ello se desglosan a continuación.

Desde el centro del sistema mundial, señaladamente Estados Unidos, se emprende una cruzada cultural que pretende imponer la hegemonía euroestadounidense. La plataforma de lanzamiento la configuran elementos geoestratégicos como la imposición del dólar como divisa internacional, las políticas neoliberales como programas de gobierno, el emplazamiento de bases militares como mecanismo disuasivo, la configuración de cadenas globales de producción a cargo de la inversión extranjera, entre otros elementos. Las llamadas industrias culturales juegan, también, un papel notable, a menudo soslayado o analizado de manera separada al imperialismo económico-político. Así como el dólar es la moneda universal, el inglés asume el papel de idioma de los habitantes cultos del planeta. Una multiplicidad de bienes culturales, de manufactura euroestadounidense, circundan el mundo y domeñan las conciencias y amenizan los momentos de descanso y esparcimiento: cine, moda, hábitos de consumo, importación de mercancías, televisión, literatura, informática, etc.

Los productos culturales de los países desarrollados inundan las periferias, pero los productos culturales de las periferias, los que pueden ver la luz, ante la embestida foránea, no corren la mismo suerte, pues difícilmente penetran los mercados del centro, y de hacerlo, hay barreras culturales que impiden su buen éxito, por lo que suelen pasar inadvertidos o como parte de efímeras manifestaciones folclóricas del subdesarrollo.

La práctica política impuesta está encajonada en la democracia representativa, y más precisamente en la democracia electoral, donde el monopolio de la representación la ejercen los partidos políticos, que se 
organizan bajo los designios de los poderes fácticos y organizan los comicios para favorecer la elección de candidatos que defiendan o preserven al menos los intereses de las élites económicas. La mayoría de los ciudadanos no dispone de la información veraz ni del conocimiento necesario para discernir las ofertas electorales ni el desempeño de gobernantes, legisladores y magistrados. El ejercicio del voto popular se constriñe a elegir personajes de la clase política que no representan a los sectores populares. En cambio, los llamados poderes fácticos tienen una alta influencia en la selección interna de candidatos y en el diseño de políticas y leyes. Esta es el tipo de democracia liberal que divulgan los países centrales, pues es consustancial al predominio del gran capital.

La ideología dominante en las periferias está moldeada por el hecho de que el agente del desarrollo, el vehículo de la modernización neoliberal, descansa en la inversión privada, sobre todo la extranjera. Una fuerza extra local proveniente del centro es el instrumento para habilitar las sociedades autóctonas y sustituir los dispositivos culturales nacionales y locales para procrear el entramado civilizatorio. Los gobiernos y demás instituciones proclaman la incapacidad de la cultura nacional para generar su propio desarrollo. No se reconoce abiertamente que la inversión privada extranjera busca, sobre todo, sustraer grandes ganancias, sin importar los costos humanos y ambientales, en cambio se plantea que generará progreso tecnológico, empleos formales y crecimiento económico.

Al influjo de las mejoras en las tecnologías de la comunicación y la comunicación y de la alianza estratégica con el poder establecido, los grandes medios de comunicación masiva amasan un poder de gran penetración en todas las capas y clases de la sociedad, en especial con los sectores subalternos. Este poder tiene un poderoso influjo cultural, pues logra colonizar la conciencia colectiva. Los principales medios del poder mediático son las televisoras comerciales que disfrutan de grandes audiencias, a las cuales influyen de manera determinante en las formas de pensar, comprar, consumir, votar, etc. En una pista semejante, aunque con otros formatos, actúan la industria cinematográfica, periodística, radiofónica y editorial. Existen algunas excepciones en algunos medios de comunicación, donde se difunden opiniones, ideas e imágenes que no pregonan el discurso del poder y que ofrecen otras formas de pensar y entender el mundo. Pero a menudo son medios alternativos con bajo presupuesto y limitada cobertura.

Los centros de investigación y docencia de los países desarrollados se distinguen por generar y divulgar conocimiento científico y tecnológico articulado por la cultura dominante, que se difunde de manera incontrolada en los países periféricos. Amplios sectores del medio académico e investigativo de los países subdesarrollados adoptan, de manera acrítica, las ideas, teorías, conceptos, técnicas y políticas diseñadas en el centro, sin oponer resistencia, y más bien con la pretensión de reflejar un aire de modernidad o posmodernidad, una sintonía con la cultura dominante. En menor medida, existe una larga tradición crítica del pensamiento del sur que pretende cuestionar la cultura dominante y plantea alternativas culturales, científicas y políticas para promover un desarrollo humano alternativo.

Amplios conjuntos sociales del sur ven como referente cultural y civilizatorio al norte. Los valores de su cultura dominante son internalizados en la propia y llevados a la práctica siempre que sea posible, lo cual facilita enormemente la incursión de las grandes corporaciones multinacionales y las políticas neoliberales que son concebidas como "responsables". Los migrantes internacionales, que van del sur al norte también idealizan a los países centrales como los paraísos para el desarrollo humano, donde podrán disfrutar del consumismo y de las prácticas sociales más civilizadas. En su interlocución, los dependientes económicos de los migrantes, que aún radican en los lugares de origen, son persuadidos de que el modelo de desarrollo del norte es el modelo a seguir. El discurso del poder difunde la percepción de que los migrantes son los agentes de la modernización que replicaran la cultura del norte en el sur. Las remesas, habilidades y destrezas, y la ideología del norte serán los instrumentos y recursos apropiados para desarrollar al subdesarrollo.

\section{Desmontaje de la cultura contemporánea}

El derrumbe del bloque soviético marcó un hito en la historia reciente de la humanidad: el sistema 
capitalista se declaró vencedor de la Guerra Fría e inició una frenética estrategia de expansión por el mundo. Los organismos internacionales impusieron en el orbe sus políticas neoliberales de ajuste estructural, las corporaciones multinacionales extendieron una red global de producción, comercialización, financiamiento e inversión, los gobiernos extendieron su hegemonía político-militar y las industrias culturales difundieron sus productos como testimonio del triunfo del mercado y el entretenimiento. En contrapartida, los países de la periferia desmantelaron su Estado social, el mercado interno y su ideología nacionalista, para conceder los espacios de privilegio a la inversión extranjera y a la cultura del capitalismo a ultranza. El concepto de globalización fue propuesto para nombrar el cambio estructural y cultural. El énfasis se puso en el ascenso de los flujos de inversión, tecnología, mercancías e información. Estábamos arribando a los umbrales de una nueva era que prometía crecimiento y prosperidad a los pueblos que se sumaran a la economía del mercado global (Harvey 2004).

La cultura dominante es una matriz que concentra poder y riqueza en las élites, pero deteriora la naturaleza y las formas de vida de la mayoría de la población. Frente a los esplendores de las manifestaciones culturales refinadas, perviven el deterioro de la sociedad y de las condiciones generales de vida y trabajo de la población, lo que supone una barrera cultural, un malestar en la cultura o una crisis civilizatoria.

El desarrollo capitalista (propulsado por el interés de la maximización de ganancia) es incapaz de generar desarrollo humano generalizado (centrado en el buen vivir, la justicia social y bien común). En su propia dinámica se incuba la expansión y profundización de las desigualdades sociales, puesto que no se trata de un proyecto de cultura general sino un proyecto de dominación de unas clases sociales sobre otras que entronizan el fetichismo cultural (plutocracia, dinero, fama; crecimiento, rentabilidad, competencia), no la equidad, libertad y ética.

El individuo abstracto e indiferenciado es la piedra de toque del pensamiento conservador y de la ideología neoliberal. Según esta apreciación, las compulsiones del egoísmo y el interés personal, o más específicamente el cálculo racional de utilidad, es el móvil de la sociedad. La preservación de la libertad individual es el enunciado del capitalismo decimonónico que ha sido trasplantado en los siglos posteriores. Como el individuo puede referirse por igual a una corporación multinacional que a un indigente, el discurso dominante hace tabla rasa de las desigualdades sociales, para terminar beneficiando, en los hechos, a los grandes intereses establecidos. Incluso se llega a postular que las desigualdades son necesarias para motivar la competencia y la economía de mercado. Valores como la solidaridad, la equidad y la justicia social son antónimos del pensamiento neoliberal, pese a que son postulados de los proyectos libertarios de la actualidad.

La compraventa de mercancías es el combustible del desarrollo capitalista. Se produce para convertir las materias primas en mercancías, incluso la fuerza de trabajo es una mercancía más (aunque la más preciada y vilipendiada a la vez). Los bienes comunes y bienes de la nación, como el agua, tierra, subsuelo, biodiversidad, entre otros elementos vitales para la cultura, se privatizan o se transforman en mercancías con miras a generar ganancias. El mundo es imaginado como un mercado mundial o un mercado total. Los países y pueblos que se resisten a incorporarse a la lógica del mercado son tachados como anacrónicos, antidemocráticos o terroristas. Con el objetivo manifiesto de apropiarse de recursos naturales estratégicos, como el petróleo, gas, minerales, se han emprendido guerras de conquista, en nombre de la democracia y la libertad.

El ritmo frenético de producción arroja al mercado una masa inconmensurable de mercancías que necesitan realizarse para que retorne al inversionista la ganancia esperada. Para ello es menester erigir una demanda efectiva, que los consumidores se vuelquen a comprar, si es posible de manera compulsiva, mercaderías de todo tipo. Algunas técnicas de persuasión, como la propaganda y la mercadotecnia, penetran el inconsciente colectivo para orientar los patrones de consumo. Pero también la difusión masiva del crédito, a través de tarjetas de crédito y demás instrumentos financieros. Los excesos crediticios desembocan, con frecuencia, es burbujas especulativas y en crisis financieras. Otro asunto es el hecho de que los desbordantes ritmos de producción están devastando aceleradamente el medio ambiente y las posibilidades de reproducción de recursos naturales potencialmente renovables, 
además de que, cada vez más, se están diseñando mercancías con una pronta caducidad programada, a fin de que el consumidor se vea en la necesidad de reemplazar a la brevedad los artículos para la vida diaria o los bienes suntuarios. El consumidor compulsivo también compra prestigio y estatus social.

La noción de democracia prevaleciente se reduce al ámbito electoral. El sistema de poder, a través de los partidos políticos, designa candidatos afines a los intereses de las élites para ofertar a la sociedad la baraja de opciones por las cuales sufragar. Los distingos ideológicos entre los flancos de derechas e izquierdas pierden sentido, porque las proposiciones de la mayoría de los contendientes son indiferenciadas. Atienden a un patrón común y se respaldan por estrategias de mercadotecnia política, no por alianzas sociales acordes a proyectos políticos que representan a sectores específicos de la sociedad. La ciudadanía, constreñida a su expresión mínima, es convocada de manera ritual a los comicios oficiales para ejercer su derecho de elegir a aquellos candidatos que le despiertan alguna simpatía o compelidos por las campañas de persuasión mediática que divulgan con profusión la imagen personal de los políticos, no las ideas, proyectos e intereses que representan. Pasado el ritual electoral y sancionado por las instancias correspondientes, la ciudadanía permanece impávida ante el ejercicio discrecional de los llamados representantes populares en los puestos del poder político. Y a lo sumo es convocada, de nueva cuenta, para ejercer un "voto de castigo" o un "voto nulo" como expresión de descontento ante la clase política. Sin embargo, no se hace un llamado a la organización y a la acción social para cambiar las estructuras de poder e instaurar un gobierno que en efecto represente los intereses concretos de la ciudadanía.

Pese a que la ideología de la globalización proclama una estandarización cultural, una adopción de conductas universales, conectadas por cierto con la oleada consumista, que en efecto sucede merced al imperialismo cultural, también se refuerzan las ideologías nacionalistas, regionalistas y localistas, según el contexto (Klein 2002). El nacionalismo es contradictorio, pues desde el punto de vista del capital, las grandes corporaciones multinacionales, cuya base operativa está instalada, las más de las veces, en los países centrales, emprende campañas para conquistar territorios en el mundo, y, de cierto modo, son emisarios culturales de las ideologías de sus países, pero reclaman que las sociedades de destino no opongan resistencias culturales y políticas, y más aún que adopten sus pautas. No obstante, los países centrales cierran las fronteras a la inversión y mercancías de las periferias cuando perciben una amenaza comercial o económica, y también cierran las fronteras a la fuerza de trabajo del Tercer Mundo.

Las élites económicas y políticas que concentran poder y riqueza, promueven una ideología que resguarda los grandes intereses establecidos y cierran el paso a los proyectos alternativos que pretenden generar procesos de transformación social a favor de las mayorías sociales. Valores tales como la democracia electoral, el libre mercado, la religión y el entretenimiento se anuncian como baluartes de las culturas modernas. Las ideas del cambio social o las que simplemente buscan ampliar los derechos humanos de las mayorías, en distintos planos y niveles, son acalladas. El poder comunicacional de los grandes medios de comunicación (prensa, televisión, cinematografía) cumplen un papel fundamental para difundir los lineamientos hegemónicos y desplazar a los alternativos o contra-hegemónicos.

Los migrantes han sido señalados como los bárbaros, los aliens, los invasores, que amenazan la civilización occidental y las certezas culturales de los países centrales o desarrollados. Los inmigrantes constituyen una amenaza, por lo que es permisible erigir muros físicos, pero también emplazar fuerzas militares y policiacas para resguardar las fronteras. Fronteras adentro, los migrantes son estigmatizados como enemigos públicos y son también criminalizados. Las cárceles están atestadas de inmigrantes y las redadas y deportaciones son nota habitual.

Las nuevas tecnologías de la comunicación y la información que ajustaban los términos de lugar y tiempo en un espacio simultáneo, en tiempo real, que ponía en sincronía las operaciones comerciales, productivas y financieras, y trastocaba las formas de organizar la producción bajo pautas de control cibernético y digital, abría la expectativa de una nueva economía, incluso de una nueva era, de un capitalismo regido por el control informacional. La computadora era el nuevo dispositivo regulador de las relaciones sociales y el internet la red de comunicación que convertía en prescindible el encuentro cara a cara. Por otra parte, la proliferación de gobiernos afines a las políticas neoliberales ganaba la escena 
electoral y afianzaba lazos de colaboración con las instituciones financieras internacionales que disponían del recetario responsable para conducir a la economía a través de las pistas de la economía de mercado. Era la anticipación del mundo feliz o, al menos, el fin de la historia. Sin embargo, las nuevas tecnologías, los nuevos mecanismos regulatorios, los gobiernos tecnocráticos y las políticas de mercado, resultaron insuficientes o incapaces para delinear los contornos de una nueva sociedad. La recurrencia de crisis sucesivas recordaban que la economía mundial estaba regida por mecanismos espurios: sobreexplotación de los recursos naturales y sobreexplotación de los trabajadores, especulación financiera. Las crisis se sucedían unas a otras, y los signos vitales del capitalismo mundial anunciaban un sobrecalentamiento de la financiarización, una precarización sin precedentes de los mercados laborales, un problema de sobreproducción, una degradación del medio ambiente y la expansión de la inseguridad humana.

El modelo de acumulación y el sistema de poder subsumen a la mayoría de las clases sociales. Los sectores subalternos padecen un acceso desigual a los medios de producción y subsistencia y a los bienes culturales. El poder comunicacional de los grandes medios de comunicación de masas inoculan en las colectividades ideas, imágenes e información que contribuyen a deformar el pensamiento subalterno y a perder conciencia de la situación de adversidad que se padece. La cultura dominante se anida en los sectores oprimidos.

La ciudadanía mínima asumida con beneplácito o indiferencia por la población genera diversas expresiones de malestar o inconformidad que no movilizan a la sociedad. Existen manifestaciones de conformismo y colaboracionismo de los sectores subalternos con los poderes aún a sabiendas de que los actos del poder dañan las condiciones de vida y trabajo de la población, pero la inconciencia social es capaz de deformar o enajenar el pensamiento y de pervertir la acción social. Por derivación, también existen formas de apatía y cinismo que afectan a los sectores sociales más inamovibles y conformistas.

El pensamiento mágico ha sido, tradicionalmente, un acicate de la subalternidad piadosa que confía en que fuerzas supremas, como las divinidades o personajes terrenales encumbrados, con su sola voluntad, pueden modificar el estado de cosas y resolver los problemas particulares de los individuos, familias y comunidades. Ante la agudización de los problemas terrenales y cotidianos, la invocación de poderes supremos se considera como el alivio para toda ocasión. La religiosidad administrada por las diversas iglesias y algunas formas de religiosidad popular constituye un medicamente auto-administrado para perpetuar las desigualdades.

El ensimismamiento de las llamadas culturas populares de ascendencia rural, como las referentes a grupos indígenas y campesinos o grupos identitarios urbanos, habitualmente marginados, como movimientos ecologistas, de preferencias sexuales y grupos juveniles, terminan por desdoblar prácticas autorreferenciales desconectadas de su entorno bajo la proclama del respeto a las diferencias y a la diversidad cultural. Estos grupos terminan por ser funcionales al orden sistémico, porque la multiculturalidad abona a la preservación de la diferenciación social como criterio de convivencia y pluralidad (Grimson 2011).

Los promotores del desarrollo a menudo internalizar las prescripciones desarrollistas del poder, como el desarrollo local o la aplicación de remesas como instrumentos del desarrollo, con la intención de generar nuevos ámbitos mercantiles en las zonas marginales y de integrar a los sectores subalternos a la dinámica económico-política de las élites.

La cooptación de movimientos y organizaciones de la sociedad civil por el gobierno y partidos políticos es una práctica muy socorrida que desarticula las prácticas autónomas y la pretensión de promover cambios en el entramado estructural e institucional. Bajo consignas como el diálogo y la negociación, los liderazgos sociales sucumben ante la seducción oficial y pierden la oportunidad de promover avances progresistas en la sociedad, a cambio de posiciones en la estructura del poder o del acceso a recursos públicos.

Los grupos subalternos más radicales articulados en movimientos u organizaciones más o menos 
establecidas suelen recurrir a estrategias de lucha social como marchas y plantones que no afectan los designios del poder, y que incluso suelen ser usadas las protestas como un pretexto para aplicar medidas represivas contra los manifestantes. La protesta social también tiende a ser espontanea, sin un programa bien articulado y con reivindicaciones que fácilmente pueden ser respondidas o ignoradas por el poder público. En última instancia, la movilización social que recurre a estos métodos de lucha significa una pérdida de energía social.

La cultura alternativa dimana de los sectores subalternos que están conscientes tanto de su situación, como de que el sistema de poder y el modelo de acumulación dominantes no representan un espacio social incluyente. Solo a partir de la conciencia social es posible advertir la necesidad de generar cambios estructurales y no simplemente reivindicaciones cortoplacistas o efectistas, que terminan por legitimar al sistema (Roitman 2012).

La enajenación del pensamiento social, la colonización de la conciencia colectiva y las diversas formas de la falsa conciencia configuran el imaginario colectivo y el sentido común que inundan el mundo subjetivo de la subalternidad. La toma de conciencia social es un requisito indispensable para la adopción de una cultura política movilizadora capaz de afrontar el desafío de promover procesos de transformación social. El trabajo intelectual que analiza, devela e informa es fundamental para concederle fundamento científico al conocimiento formador de conciencia. Pero también es primordial el interés y autoconocimiento de los sectores sociales interesados en promover alternativas sociales de desarrollo.

Entre los teóricos de la ciencia política suele aducirse que las instancias más eficaces para la organización social son los partidos políticos. En la realidad, los partidos afrontan una profunda crisis de representatividad, puesto que en lugar de organizar y representar a sectores concretos de la sociedad, terminan por representarse a sí mismos, es decir, la llamada clase política se organiza a través de los partidos políticos con el fin de controlar el monopolio de la representación política y acceder a través de estos instrumentos a puestos del poder político, además de sustraer partidas del erario público, detentar privilegios y fama pública. La representación directa de la sociedad civil sólo puede darse a través de instancias de organización autónoma frente a los poderes del Estado e independiente de grupos de interés y partidos políticos que representan intereses elitistas.

La noción de cambio ha sido reducida a la idea de alternancia electoral, donde personajes de la clase política registrados formalmente por partidos políticos distintos se suceden la titularidad del poder político pero al amparo de un programa de gobierno común, de corte neoliberal. La meta de cambiar las estructuras de acumulación para reorientar los esfuerzos sociales en la generación de riqueza y sus mecanismos de distribución bajo criterios de equidad y justicia social y el cambio del sistema de poder para instaurar un gobierno que en efecto represente los intereses concretos de la ciudadanía son los ejes fundamentales de un proyecto alternativo.

\section{Resquebrajamiento societal}

Los estudios socioculturales sobre la violencia han puesto el énfasis en la conflictividad interpersonal como ámbito social de la violencia desencadenada en las familias, barrios y colonias, principalmente de sectores pobres y marginados. Desde esta mirada, la violencia es, sobre todo, simbólica y agrede la identidad de grupos sociales como indígenas, mujeres, jóvenes, discapacitados, homosexuales, migrantes, etcétera. La violencia microsocial está en el foco de la atención.

Las violencias estructurales, políticas e institucionales inmersas en la lógica del funcionamiento del sistema capitalista han sido omitidas. El capital y el poder, representados por las grandes corporaciones multinacionales y el Estado despliegan una práctica estratégica que atenta sistemáticamente en contra de la mayoría de las clases sociales y del medio ambiente, a fin de garantizar la reproducción del sistema de valorización del capital y la preservación de las relaciones de dominación. A fin de garantizar la maximización de la ganancia se incurre en prácticas que hacen de lo irracional el modo racional de convivencia social. Las relaciones sociales de explotación, despojo, dominación y opresión a cargo del 
capital y el poder se diluyen, incluso se legitiman o pasan como sacrificios sociales en aras de los grandes fetiches del desarrollo: crecimiento, inversión, empleo y riqueza (Márquez y otros 2012).

Para entender las raíces de la conflictividad social y de las múltiples expresiones de la violencia, es menester desmenuzar las prácticas estratégicas a cargo de las grandes corporaciones del capital nacional y multinacional y de las diversas instancias que conforman el sistema de poder.

Un dato sintomático de las luchas del capital contra el trabajo es la prolongada y extensa guerra contra el trabajo vivo, sus organizaciones autónomas y su calidad de vida. El ataque sistemático en contra de los trabajadores, sus organizaciones, prestaciones y condiciones de vida es uno de los ejes primordiales del neoliberalismo. Las que pudieran considerarse como conquistas históricas de los trabajadores, como la legislación laboral, el salario social, el salario remunerativo y la protección estatal, se desmantelan. En su lugar, se impone un régimen de inseguridad laboral y de superexplotación, que legitima el despido libre, además del incremento de la jornada e intensidad laboral y la disminución salarial.

La red de protección social en materia de salud, educación, vivienda, empleo, alimentación, además de los servicios públicos como abasto de agua potable, recolección de basura, construcción de infraestructura, transporte público, todo este entramado es desincorporado del Estado para cederlo, de manera tajante o gradual, al capital privado para saciar su sed de ganancia.

El nuevo orden agroalimentario mundial, controlado por los monopolios y oligopolios transnacionales, controlan la producción y distribución de alimentos, y someten a estas mercancías a mecanismos especulativos de corte bursátil y financiero que encarece el precio de los comestibles y repercute en el acceso de los pobres a alimentos sanos, nutritivos y suficientes, tanto para garantizar la supervivencia como para reproducir las energías vitales del trabajo vivo, única posesión para concurrir al mercado laboral.

Los sujetos despojados, excluidos y marginados son reducidos por el sistema de poder y acumulación a su condición de mercancía humana, a una forma corporal de trabajo vivo, cada vez más superexplotados y necesitados. Las dinámicas estructurales, políticas e institucionales vulneran, sistemáticamente, las condiciones de vida y trabajo, mientras que las instituciones pretenden suavizar los estragos con políticas asistencialistas otorgando dádivas o paliativos para los pobres extremos. Esta política ha sido nombrada como "guerra contra la pobreza".

Derivado de las estrategias imperiales globales, se implementa la guerra contra el terrorismo, la criminalidad organizada y la inseguridad. En los países periféricos, como Colombia, México, Afganistán, El Congo y demás, el crimen común y organizado genera una espiral de violencia que atenta contra la ciudadanía inerme, merced a vacíos de poder o, incluso, colusión del poder político y empresarial. Las acciones delictivas se diversifican, desde narcotráfico, tráfico de personas, trata de personas, tráfico de órganos, piratería, fraude cibernético, extorsión, secuestro, tortura y demás. Se forman asociaciones de bandas criminales con grupos empresariales, políticos y policiacos para controlar una fuente de riqueza, que entraña una fuerte dosis de violencia. Las mafias del poder prohíjan conglomerados empresariales, financieros y políticos que articulan actividades ilícitas, como el narcotráfico, la trata de personas, la extorsión, el secuestro, el tráfico de personas y el tráfico de órganos. Estas actividades son altamente lucrativas y actúan bajo un velo de impunidad y corrupción. Con ese pretexto, los gobiernos con talante autoritario militarizan la sociedad, en parte para intimidar a los sectores rebeldes y opositores y en parte para propagar el miedo entre los sectores medios desinformados y fácilmente atemorizados. Esta estrategia no atenta, sin embargo, contra el corazón financiero del crimen organizado. En cambio, está orientada a promover el respaldo de algunos sectores de la ciudadanía al incremento de medidas coercitivas y punitivas que terminan por reforzar la violencia del Estado y la criminalización de los sectores más vulnerables. Las bandas criminales reclutan a jóvenes sin futuro para que jueguen el papel de carne de cañón, es decir, sicarios o pistoleros que movidos por el dinero fácil están dispuestos a matar o a morir. La criminalización de los excluidos, pobres y necesitados acontece por todas las vías: gubernamental y criminal. Y se complementa con estrategias fascista de limpieza social que pretende exterminar a los pobres de la calle porque afean la ciudad a ojos de los potentados, de exterminio de 
grupos rebeldes mediante la activación de grupos paramilitares o escuadrones de la muerte que imponen la ley de los poderes fácticos en territorios bajo su dominio.

La ideología o doctrina de la seguridad nacional está incubada en el proyecto de globalización neoliberal, centrada en los intereses geoestratégicos de las grandes potencias capitalistas, donde tienen su sede las grandes empresas multinacionales, es decir, los monopolios u oligopolios industriales, comerciales, financieros y de los servicios. Bajo la noción de seguridad nacional se han emprendido guerras de conquista, con el argumento de la "guerra contra el terrorismo" y la guerra preventiva, asimismo como un supuesto afán de expandir el reino de la libertad, la democracia y la economía de mercado, valores enarbolados por Estados Unidos, y sus aliados europeos, Inglaterra a la cabeza. En estas guerras existe el antecedente de que los territorios invadidos son ricos en recursos naturales, como petróleo y gas, como sucede en Irak. Un amplio despliegue de bases militares en el mundo tensan las relaciones políticas y diplomáticas. En estos episodios bélicos se registran innumerables pérdidas en vidas humanas, además de la destrucción de ciudades, poblados e infraestructura, y la devastación de las relaciones sociales (Klein 2007).

También al amparo del mismo expediente militar se emprende una "guerra contra el narcotráfico", que combina el imparable trasiego de drogas con el contraflujo de armas y la expansión de la violencia. Las mafias del crimen organizado consolidan, mientras tanto, un espacio de poder que preserva una fuente inconmensurable de ganancias, la cual está articulada con el sector empresarial y político. Los gobiernos de los países con alta incidencia criminal y muertes violentas han sido caracterizados como Estados fallidos, y son un blanco fácil para la imposición de políticas por los Estados de los países centrales.

Bajo esa misma ideología también existe una estrategia de control de la migración, que adquiere tintes más dramáticos en aquellos casos donde se pretende imponer un muro o dique a la entrada masiva de inmigrantes pobres, como sucede con el Muro Fronterizo en la frontera entre México y Estados Unidos, la Fortaleza europea, para cerrar el paso a los africanos en Europa y el Muro de Gaza, para separar a palestinos de israelíes. Los migrantes están padeciendo condiciones inhumanas, de alto riesgo, en su intento por acceder a países de mayor desarrollo relativo (Castles y Delgado 2008).

Las desigualdades sociales generan condiciones de inseguridad humana de carácter multidimensional: laboral, social, alimentaria, pública. Los pobres y excluidos padecen las peores condiciones de vida y trabajo. Con la pretensión de aminorar el riesgo de estallido social, los gobiernos ejecutan una llamada "guerra contra la pobreza" que consiste en otorgar dádivas a la población catalogada como extremadamente pobre.

\section{Ruptura civilizatoria}

Las dimensiones de la crisis del capitalismo contemporáneo han sido reducidas al corto plazo, el año de 2007-2008; un sector, el financiero, especialmente el hipotecario; y un país, Estados Unidos, sólo que el país es nada menos que la principal potencia capitalista del orbe, por lo que sus secuelas se dejaron sentir en todos los rincones del orbe. La crisis fue caracterizada como una $\mathrm{V}$, una caída abrupta que tendría, sin embargo, una súbita recuperación; como un L, una caída con un periodo de estancamiento, pero al fin estabilidad, y una $\mathrm{W}$, una caída, una recuperación y una nueva caída. En todo caso, ha sido vislumbrada como un problema de carácter cíclico, temporal y perentorio. Se trata de mecanismos visuales para dibujar la trayectoria del crecimiento o decrecimiento económico, variable donde se pretende sintetizar la vida social, política, cultural y ambiental de la humanidad. Esta forma de entender la crisis y el presente es harto limitada.

El rasgo más preocupante es que el sistema mundial capitalista, en su conjunto, atraviesa por una profunda crisis estructural y sistémica que pone en entredicho no sólo el proceso de valorización del capital, que en eso se expresa la depresión económica mundial, el desempleo estructural y el desplome del crecimiento, sino la reproducción de la vida humana. La propia subsistencia de las clases sociales más pobres afronta múltiples riesgos y peligros. La insustentabilidad social es el rasgo dominante del 
La economía mundial se ha monopolizado y, en contrapartida, el desempleo estructural aumenta. La masa de trabajadores desempleados y pauperizados en el mundo se ensancha a niveles intolerables e insostenibles, por diversos motivos: la imposición de políticas de flexibilización y precarización laboral para reducir los costos laborales e intensificar las ganancias corporativas; la implantación de nuevas tecnologías que convierten en prescindibles a una masa mayor de trabajo vivo; la estrategia de las empresas de despedir periódicamente personal para negociar a la baja salarios y prestaciones, desvincular a los obreros de antigüedad, prestaciones y debilitar el poder de negociación de los sindicatos y desplazar faces del proceso productivo hacia empresas que funcionan, de manera subordinada, como subcontratistas. Asimismo, la irrupción de crisis económicas golpea, antes que a nada, a los trabajadores, asalariados y no. La válvula de escape de los capitales en apuros es pasar la factura a la clase trabajadora, incluso esa ha sido una exigencia planteada por los gobiernos que destinaron paquetes de "rescate" a las empresas que implementaran programas de "competitividad laboral", es decir, que despidieran personal y contuvieran o redujeran los niveles salariales (Bello 2006, Foster y Magdoff 2009).

El sistema agroalimentario mundial ha desencadenado una pérdida de soberanía alimentaria. La mayoría de países subdesarrollados ha perdido la soberanía alimentaria, es decir, la capacidad de producir los alimentos básicos que demanda su propia población y la concomitante capacidad de los consumidores por acceder a alimentos sanos, inocuos y nutritivos, según los requerimientos de una dieta suficiente para mantener un estado aceptable de salud en condiciones normales. Las grandes empresas agroindustriales controlan el sistema alimentario mundial, y son capaces de imponer semillas, pesticidas, fertilizantes, patrones de cultivo y sistemas de producción y riego, esquemas de financiamiento, sistemas de comercialización y distribución, así como patrones de consumo y sistemas de precio en conjunción con los grandes monopolios comerciales. En los países subdesarrollados, la mayoría de la población, en especial los niños y adultos mayores, padecen hambrunas, desnutrición y obesidad, este último merced a la imposición de alimentos con alto contenido calórico, pero baja densidad nutritiva (los llamados alimentos "chatarra").

La depredación del medio ambiente entraña una fractura del metabolismo social. El acortamiento de la vida útil de las tecnologías producidas por las corporaciones que habilitan mejoras tecnológicas en sus procesos productivos y en el propio diseño de las mercancías, significa el incremento del ritmo de rotación del capital constante o de la dinámica de acumulación. De este modo, los valores de uso pronto se convierten en artículos desechables, con lo cual se arroja una mayor cantidad de desperdicios y basura al medio ambiente, al tiempo en que se activa el ritmo de producción, es decir, la demanda de insumos productivos provenientes de la infraestructura natural. El ritmo de remplazo de la maquinaria, equipo, edificios e infraestructura también se inscribe en esta lógica de aceleración del ciclo de producción y consumo. El incesante ritmo productivo rebasa, con mucho, la capacidad de remplazo de la naturaleza. Los problemas ambientales se multiplican: erosión, sequías, inundaciones, cambios en el clima, pérdida de biodiversidad. En suma, se deterioran las bases naturales para la producción y se fractura el metabolismo social entre sociedad y naturaleza.

Las fuentes de energía, un recurso vital para la organización socioeconómica, resiste los embates de la especulación y de violencia. La conclusión del pico en la producción de combustibles fósiles, principalmente petróleo, ha desencadenado estrategias de guerras de conquista, bajo el señuelo de guerras preventivas, guerras contra el terrorismo o guerras en pro de la democracia y la libertad, que ha sembrado la muerte y el terror en poblaciones donde abunda las mayores reservas de hidrocarburos en el mundo, y anuncia el riesgo a países subdesarrollados que disponen de petróleo, pero que no se han plegado a los tratados comerciales o permitido la entrada de inversión extranjera en este campo. La búsqueda de alternativas energéticas es un campo en ciernes en la investigación científico-tecnológica, pero principalmente un territorio de alta concentración corporativa, que anticipa el control empresarial en materia energética. 
recurso para la subsistencia. Durante la globalización neoliberal, las migraciones adquieren un nuevo papel dentro de la división del trabajo. Los mecanismos del desarrollo desigual generan condiciones estructurales, como el desempleo y las desigualdades, que empujan las migraciones masivas de conjuntos poblacionales despojados y excluidos. Literalmente expulsadas de sus territorios, las personas en estas condiciones se desplazan a otros lugares, del propio país y el extranjero, compelidos por la necesidad de acceder a medios de subsistencia u oportunidades de movilidad social. La sobreoferta laboral y el creciente deterioro de las condiciones de vida, confieren a las migraciones, en particular las provenientes de países periféricos, el carácter de desplazamiento forzado. La migración forzada interna e internacional caracteriza al grueso de los movimientos poblacionales bajo el capitalismo neoliberal. La matriz propulsora de las migraciones está compuesta por las violencias estructurales, políticas e institucionales y la condición de inseguridad humana que aqueja a los pobres de la tierra. Las migraciones forzadas tienen tres características en común: a) se verifican en los planos nacional e internacional, preponderantemente desde las regiones deprimidas de las periferias con destino a regiones relativamente más prosperas de las periferias o el centro; b) afectan primordialmente a los sectores vulnerables, pobres y excluidos que no disponen de basamentos materiales y subjetivos para garantizar la supervivencia o alimentar una expectativa de vida decorosa; c) generan una sobreoferta de trabajo barato y desorganizado que es aprovechada por empleadores y corporaciones interesadas en abaratar costos; y d) alimentan los mecanismo de exportación directa e indirecta de fuerza de trabajo, tanto de trabajo inmediato y como de trabajo científico-tecnológico.

La imposición de patrones de consumo, formas de pensar, de vestir y actuar carcome los procesos de socialización y produce identidades individualistas y consumistas. El influjo de la industria del entretenimiento, encabezadas por el cine de Hollywood y la televisión comercial, aunado a la degradación inducida del sistema educativo prohíjan una ciudadanía precaria.

El fetichismo del poder político forma parte del expediente de una cultura crítica en crisis. Sobre el modelo neoliberal y su clase política postulante se cierne la deslegitimación, en tanto que asistimos a la entronización de los poderes fácticos y las coaliciones turbias de los partidos. En contrapartida, se promueva la despolitización de la sociedad, la destrucción de sujetos sociales colectivos, en beneficio de un ciudadano mínimo, individualista, egoísta y conservador. El saldo es contrastante, por una parte la sensación de desánimo y apatía, y, por la otra, expresiones de resistencia y rebelión.

La imposición del pensamiento único, neoliberal, afianza marcos analíticos con una manifiesta incapacidad para entender el presente. La importación inmisericorde de teorías y conceptos es un recurso a la moda que, no obstante, inviste de prestigio autoral. El pensamiento crítico es olvidado o motejado como anquilosado.

Bajo la visión convencional sobre la crisis (financiera, de corto plazo, asentada en Estados Unidos), los inmigrantes resultan estigmatizados como responsables de la crisis. En el contexto de la crisis general del capitalismo, la población migrante es señalada como culpable de la crisis, y surgen legislaciones y políticas de corte abiertamente represivo y anti-inmigrante. Acontece una pérdida sensible de empleos, mientras que las condiciones de los que logran conservarse se deterioran y desembocan en deportaciones. El resultado visible es la drástica degradación del nivel de vida de las y los migrantes y sus dependientes económicos. Sin embargo, no prospera la expectativa de retornos masivos de migrantes y el desplome de los flujos de remesas, pero hay evidencias de que, en otro sentido, el flujo de nuevos migrantes laborales disminuye.

\section{Cambio cultural y transformación social}

Para acometer las causas de fondo, de índole histórica, estructural, institucional y política, de la problemática de descomposición social trazada por el ascenso de la violencia, inseguridad, migración forzada y crisis civilizatoria se requiere no sólo un cambio en el modelo de acumulación y en el sistema de poder, sino también un cambio civilizatorio, un cambio cultural. 
La noción de cultura se refiere al sistema de valores y prácticas de clases, grupos y movimientos sociales acordes a su visión del mundo e intereses materiales y subjetivos. Ante la persistencia de la cultura hegemónica, correlativa a los intereses del gran capital y poderes fácticos, que se engloban en el proyecto neoliberal, la cual repercute en la descomposición social generalizada, es menester impulsar un profundo cambio cultural, no sólo afincado en los intereses de los sectores subalternos y en la necesidad de rehabilitar los espacios vitales del medio ambiente, sino que además es urgente afincar relaciones sociales dignas y sustentables.

Una noción alternativa de desarrollo parece necesaria para orientar los afanes del cambio cultural. La idea de desarrollo dominante privilegia, bajo diferentes ropajes, la necesidad imperiosa del capital por allegarse la máxima ganancia posible mediante distintas estrategias, como la superexplotación del trabajo vivo, la depredación de la naturaleza como insumo productivo desechable, la especulación financiera y la privatización del conocimiento, saberes e innovaciones. Esas coordenadas y pulsiones del gran capital atentan contra el sistema de reproducción de la vida humana, pues en vastos ámbitos territoriales y sociales se padece desempleo, pobreza, enfermedad, hambre y muerte. Hoy en día, los frutos de la ciencia y la tecnología han superado las fronteras de lo imaginable por las generaciones precedentes; la capacidad de producción no conoce límites y un verdadero cúmulo de mercancías desquicia los sentidos de los consumidores; pero también las desigualdades sociales se han acrecentado de manera insospechada hasta un punto que la noción de humanidad se ha fragmentado y pulverizado dada la diferenciación radical entre clases sociales dominantes y subalternas, entre elites sociales y sectores desposeídos.

En ese contexto, la noción de desarrollo pierde sentido cuando se invoca en defensa de la humanidad. Sin embargo, más que nunca es necesario apostar por un verdadero desarrollo humano. Pero no por uno que simplemente proponga dotar de capacidades y habilidades a los sectores marginados para que se conviertan en nuevos concurrentes del mercado, sino en un desarrollo humano que desmonte el entramado de relaciones sociales que obstruye de manera decidida el desarrollo individual y colectivo de los contingentes humanos.

Desde una epistemología de las alternativas o perspectiva del sur, se postula la necesidad de generar alternativas sociales para grupos, clases y sectores sociales subalternos que promueven mejoras en el modo de vida, trabajo y convivencia (Márquez y Delgado 2011a y 2011b). En esta perspectiva el desarrollo humano concita la búsqueda de cuatro grandes metas sociales:

1) La supresión de las relaciones sociales de explotación, opresión, humillación, despojo, discriminación, criminalización y dominación.

2) La desaparición de cualquier forma de violencia estructural, política, institucional y simbólica y la generación de condiciones de inseguridad para la mayoría de las clases sociales, así como la prevención de conflictos, riesgos, peligros y vulnerabilidades.

3) La construcción de una economía para la vida, una bioeconomía, que garantice la producción y reproducción de la vida humana, en un contexto planetario rehabilitado.

4) La consecución del bien común, la justicia social y la democracia plena.

En las regiones periféricas persiste un bloque social conservador que obstruye cualquier avance revolucionario, democrático o progresista, e impone una agenda neoliberal profunda, plagada de regresiones sociales que repercuten en la descomposición social, al tiempo que refuerzan los lazos de dependencia frente a las potencias imperiales y cierran los caminos de negociación con naciones que enarbolan proyectos de integración progresistas. El gran desafío es remover ese bloque dominante y promover estrategias de cambio que consoliden avances progresistas, preparen otros avances y generen una integración regional progresista.

Dado que un proyecto alternativo de desarrollo humano se opone a las prédicas neoliberales, su materialización enfrenta obstáculos colosales, pues es necesario afectar los intereses establecidos de las 
élites sociales. El desarrollo humano es, por tanto, un proceso arduo de construcción social, un proyecto colectivo de transformación social que tiene el cometido de mejorar sustancialmente la calidad de vida y trabajo de la mayoría de la población. Un proyecto de tal envergadura no será asumido por los gobiernos comandados por bloques de poder conservadores ni por las corporaciones multinacionales que detentan el control de los hilos económicos y políticos. Por ello se precisa de la emergencia de un poder social, que en principio es un contrapoder que se opone el sistema de poder oligárquico, pero que se convierte en una fuerza social autónoma e independiente que busca el cambio social, cultural y político.

Para la formación de un poder social emergente, es necesario afianzar una nueva cultura política. En la actualidad, la enajenación que padecen la mayoría de las clases sociales se asemeja a un efecto anestésico propinado por la poderosa industria de la comunicación que constituye la principal fuente de información y entretenimiento de la población. Desde los medios electrónicos se ejerce un control de la conciencia colectiva que no tiene parangón con el efecto libertario que pudiera estar contenido en análisis críticos de la realidad en algunos medios de la prensa escrita, libros y trabajos académicos. El antídoto es la organización social entre iguales, entre miembros de clases, grupos y sectores sociales que comparten problemas comunes. El autoconocimiento, el situarse en el mundo, el palpar la realidad y las vías de solución son caminos que conducen hacia la toma de conciencia social. Pero para que esto sea posible se requiere que las organizaciones gocen de autonomía e independencia, frente a los poderes públicos, partidos políticos, poderes fácticos y medios de comunicación.

Desde la organización de la sociedad civil se pueden emprender gestiones para reconstruir el Estado, desprenderlo de los intereses oligárquicos y afianzar la responsabilidad social del poder político; asimismo intervenir los mercados para retirarlo del control monopólico que ejercen las grandes corporaciones multinacionales y reconstruir el tejidos socioproductivo. En esas condiciones, es posible dignificar el empleo como un mecanismo de contribución social para la generación de riqueza, el basamento para una mejor distribución social y un mecanismo de realización personal. El poder social es el preámbulo para la realización de una democracia plena, que conjugue los mecanismos de la democracia representativa y directa con miras a lograr la democracia económica y social.

\section{Elementos culturales para la transformación social}

El desarrollo alternativo es un proceso de invención social que requiere la aplicación de energías sociales críticas y creativas. Además de una nueva cultura política y una práctica orientada por el poder popular con representación efectiva en las diversas instancias del Estado, resulta imprescindible articular los elementos educativos, científicos, tecnológicos, artísticos y humanísticos en el proyecto de desarrollo alternativo (Márquez y otros 2012).

El sistema educativo, sobre todo el de carácter público, ha sido señalado como un espacio atractivo para la privatización, pues además de que es una fuente lucrativa por el cobro de colegiaturas y de los múltiples servicios asociados, es un vehículo preciado para formar a las nuevas generaciones bajo el manto de determinada ideologías políticas y religiosas. Los gobiernos conceden al sector privado la conducción del proceso educativo desde los niveles de pre-escolar, básico, medio superior, superior y posgrado. Aunado al problema de la creciente mercantilización, se aúna la noción de capital humano, donde el educando es formado, de manera preferente, en habilidades y destrezas técnicas, para desempeñarse posteriormente como obrero o como directivo empresarial, según el enfoque de clase. Las asignaturas y materias orientadas por las ciencias sociales y las humanidades pierden, de manera drástica, presencia. Los sistemas educativos, sus dinámicas didácticas y pedagógicas, recrean una atmósfera de "competencias" entre los educandos que son formados como agentes del mercado, que tendrán que adquirir competencias y capacidades para afrontar los desafíos del mercado laboral bajo preceptos del emprendurismo. Bajo esa tesitura, por ejemplo, los investigadores y académicos deben dedicar una buena parte de su tiempo para atraer recursos financieros de fondos públicos y privados para sufragar el gasto corriente y los proyectos académicos de su institución. Otra noción cara es la de sociedad del conocimiento, según la cual las nuevas tecnologías de la información y la comunicación 
están modificando la estructura y funcionamiento del sistema educativo y la de otras instituciones, por lo que es insuficiente entender la educación pública como una cruzada alfabetizadoras, porque también se requiere adiestramiento en el uso de tecnología digitales. Ante el paradigma de educación por competencias y capacidades técnicas y la formación de capital humano, el cambio del sistema educativo reclama también la formación humanista y solidaria para procrear en las nuevas generaciones una cultura de la vida y el desarrollo humano, antes que el egoísmo y la competencia compulsiva.

El conocimiento científico es el basamento para organizar la producción y distribución. Las grandes corporaciones multinacionales basan en ello la obtención de ganancias extraordinarias. En el periodo reciente se han registrado avances en microelectrónica, biotecnología, nanotecnología, nuevos materiales, comunicación e información. Los países que carecen de innovación tecnológica derivada de la investigación científica se caracterizan como subdesarrollados y dependientes. Un cambio sustantivo está aconteciendo, la subsunción del trabajo de científicos, tecnólogos, consultores, ingenieros e intelectuales por las grandes corporaciones. Los financiadores de la investigación científica, el Estado y fondo privados, están privilegiando la investigación aplicada a la empresa, es decir, a la generación de plusganancia, no a la satisfacción de necesidades sociales ni a la promoción del desarrollo humano. Sin embargo, también existe una tendencia regresiva: el rentismo tecnológico, es decir, el controlar de los sistemas de innovación bajo el sistema de patentes, registro de marcas, franquicias. La sociedad en general no dispone de mecanismo para ejercer un control social sobre la innovación ni sobre el consumo de productos de alta tecnología.

El desarrollo humano no sólo descansa en la formación de las nuevas generaciones en el sistema educativo ni en la aplicación de los avances de la ciencia y tecnología. Además es fundamental impulsar el trabajo crítico y creativo propio de las artes y las humanidades. El trabajo artístico no sólo nos remite al goce de las expresiones de la estética y la belleza plasmadas en la literatura, artes plásticas, música, artes escénicas, cinematografía, entre otras manifestaciones, sino que también representa un mundo espiritual que configura el sentido de lo humano a la vida en sociedad. La recreación de los valores humanos a través de las artes es un momento crucial en el entramado civilizatorio.

El conocimiento científico no puede reducirse a la ciencia aplicada, es decir, al conocimiento utilitarista, sino que también requiere de un contenido y orientación ética. De igual forma, la educación no puede estar constreñida a la formación de "capital humano", es decir, a fuerza de trabajo calificada técnicamente según las exigencias de empleadores y, en general, del mercado laboral. Pensar en un desarrollo humano alternativo también significa en formar nuevas generaciones o una ciudadanía crítica, creativa y participativa para promover los cambios necesarios y alcanzar estadios de bien común y equidad social.

\section{Bibliografía}

Amin, Samir

2010 Global History - a View from the South. Oxford, Pambazuka Press.

Castles, Stephen (y Raúl Delgado Wise)

2008 Migration and Development: Perspectives from the South. Geneva, IOM.

Bello, Walden

2006 "The Capitalist Conjuncture: Over-accumulation, Financial Crises, and the Threat from Globalisation", Third World Quarterly, vol. 27, nº 8: 1345-1368.

Dussel, Enrique

2011 Ética de la liberación en la edad de la globalización y la exclusión. Madrid, Editorial Trotta. 
Foster, John Bellamy (y Fred Magdoff)

2009 The great financial crisis: causes and consequences. Nueva York, Monthly Review Press.

Grimson, Alejandro

2011 Los Límites de la Cultura: Crítica de las Teorías de la Identidad. México, Siglo XXI.

Harvey, David

2004 El nuevo imperialismo. Madrid, Akal.

Klein, Noemi

2002 No logo: El poder de las marcas. Madrid, Paidós.

2007 La doctrina del shock: El auge del capitalismo del desastre. Madrid, Paidós.

Márquez, Humberto

2009 "Diez rostros de la crisis civilizatoria del sistema capitalista mundial", Problemas del desarrollo, vol. 40, no 159: 191-210.

2010 "La gran crisis del capitalismo neoliberal". Andamios, nº 13: 57-84.

Márquez, Humbert (y Raúl Delgado)

2011a "Una perspectiva del sur sobre capital global, migración forzada y desarrollo alternativo", Migración y Desarrollo, vol. 9, nº 16: 3-42.

2011b "Signos vitales del capitalismo neoliberal: Imperialismo, crisis y transformación social". Estudios Críticos del Desarrollo, vol. I, nº 1: 11-50.

Márquez, Humbero (Raúl Delgado y Roberto García Zamora)

2012 "Violencia, inseguridad e insustentabilidad social en México: necesidad de un parteaguas civilizatorio", Estudios críticos del desarrollo, vol. 2, nº 2: 167-197

Mora, Henry

2008 "Una reflexión introductoria sobre la naturaleza de la actual crisis global y los límites del capitalsimo", Ciencias económicas n² 2: 45-53.

Roitman, Marcos

2012 Los indignados. El rescate de la política. Madrid, Akal. 